\section{Os Fulni-ô: múltiplos olhares em uma contribuição para o reconhecimento da sociodiversidade indígena no Brasil}

\author{
Por Edson Silva \\ Universidade Federal de Pernambuco \\ (edson.edsilva@hotmail.com)
}

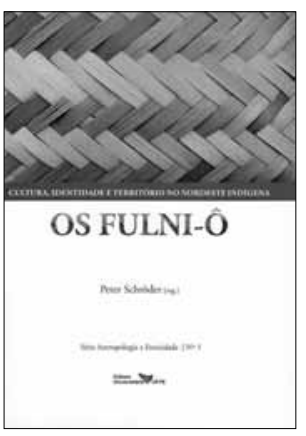

SCHRÖDER, Peter

(Org.). Cultura, identidade e território no Nordeste indígena: os Fulni-ô. Recife: Editora Universitária da UFPE, 2012. 262 p. ISBN $978-85-415-$ 0022-7

Em se tratando dos 'índios', no geral e mesmo ainda no meio acadêmico, após alguns anos de pesquisa e de convivência nesse ambiente com colegas de diferentes áreas do conhecimento, constatamos que um dos maiores desafios é a superação de visões exóticas para abordagens críticas, aprofundadas sobre a história, a sociodiversidade indígena e as relações desses povos com e na nossa sociedade. Sobretudo quando dizem respeito a povos como os Fulni-ô, falantes do yaathe e do português, único povo bilíngue no Nordeste (excetuando o Maranhão), habitando em Águas Belas, no agreste pernambucano, a cerca de 300 km do Recife.

Sobre a sociodiversidade indígena em nosso país, o índio Gersem Baniwa (os Baniwa habitam as margens do rio Içana, em aldeias no alto rio Negro e nos centros urbanos de São Gabriel da Cachoeira, Santa Isabel e Barcelos/AM), mestre e recém-doutor em Antropologia pela Universidade de Brasília (UnB), publicou o livro "O índio brasileiro: o que você precisa saber sobre os povos indígenas no Brasil de hoje", no qual escreveu:

\begin{abstract}
A sua diversidade, a história de cada um e o contexto em que vivem criam dificuldades para enquadrá-los em uma definição única. Eles mesmos, em geral, não aceitam as tentativas exteriores de retratá-los e defendem como um princípio fundamental o direito de se autodefinirem (Baniwa, 2006, p. 47).
\end{abstract}

Após discorrer sobre a complexidade das organizações sociopolíticas dos diferentes povos indígenas nas Américas, questionando as visões etnocêntricas dos colonizadores europeus, o pesquisador indígena ainda afirmou:

\begin{abstract}
Desta constatação histórica importa destacar que, quando falamos de diversidade cultural indígena, estamos falando de diversidade de civilizações autônomas e de culturas; de sistemas políticos, jurídicos, econômicos, enfim, de organizações sociais, econômicas e políticas construídas ao longo de milhares de anos, do mesmo modo que outras civilizações dos demais continentes europeu, asiático, africano e a Oceania. Não se trata, portanto, de civilizações ou culturas superiores ou inferiores, mas de civilizações e culturas equivalentes, mas diferentes (Baniwa, 2006, p. 49)
\end{abstract}

$\mathrm{Na}$ Introdução do livro aqui resenhado, o organizador da coletânea, Peter Schröder, de forma bastante emblemática e provocativa, afirmou: "É fácil escrever alguma coisa sobre os Fulni-ô". Para isso, bastaria recorrer a uma bibliografia existente. Mas, no parágrafo seguinte, Schröder enfatiza o quanto é difícil escrever sobre aquele povo indígena diante do desconhecimento resultante de barreiras impostas pelos Fulni-ô, que impedem o acesso à sua organização sociopolítica e às expressões socioculturais, notadamente a língua e o ritual religioso do Ouricuri. Os índios também contestam e questionam escritos a seu respeito, elaborados por pesquisadores, mais especificamente pelos antropólogos.

Após o texto onde o organizador da coletânea procurou situar de forma resumida a história territorial Fulni-ô, segue-se o texto de Miguel Foti, que resultou

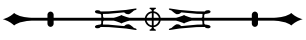


de trabalho de campo para a dissertação de mestrado defendida na Universidade de Brasília em 1991, no qual procurou descrever e refletir sobre o universo simbólico Fulni-ô baseado na resistência do segredo das expressões socioculturais daquele povo indígena.

O texto seguinte, de Eliana Quirino, que teve uma promissora trajetória de pesquisadora interrompida com o seu falecimento em outubro de 2011, é uma discussão baseada principalmente na sua dissertação de mestrado em Antropologia, defendida na Universidade Federal do Rio Grande do Norte. Tendo como base as memórias Fulni-ô, a exemplo do aparecimento da imagem de Nossa Senhora da Conceição, a participação indígena na Guerra do Paraguai, a marcante e sempre rememorada atuação do Padre Alfredo Dâmaso em defesa dos índios em Águas Belas, a autora analisou como essas narrativas são fundamentais para a afirmação da identidade indígena e os direitos territoriais reivindicados.

Um exercício em discutir a identidade étnica a partir do próprio ponto de vista indígena foi realizado no texto seguinte, por Wilke Torres de Melo, indígena Fulni-ô formado em Ciências Sociais pela Universidade Federal Rural de Pernambuco e atualmente realizando pesquisa de mestrado sobre o sistema político Fulni-ô. Em seu texto, Wilke procurou evidenciar as imbricações entre identidade étnica e reciprocidade entre os Fulni-ô, discutindo as relações endógenas e exógenas de poder, vistas a partir dos princípios da união, do respeito e da reciprocidade, baseados na expressão Fulni-ô Safenkia Fortheke, que, segundo o autor, caracteriza e unifica aquele povo indígena.

A participação de Wilke na coletânea é significativa por se tratar de uma reflexão 'nativa'. Além disso, como informou o organizador na introdução do livro, numa iniciativa inédita, antes da publicação todos os artigos foram enviados ao pesquisador indígena para serem discutidos entre os Fulni-ô, como forma de apresentarem sugestões e as 'visões indígenas' sobre o conteúdo dos textos.

Uma contribuição com uma abordagem diferenciada é o artigo de Carla Siqueira Campos, resultado de sua dissertação em Antropologia, na Universidade Federal de Pernambuco (UFPE), na qual a autora discute a organização e produção econômica Fulni-ô, fundadas no acesso aos recursos ambientais do Semi-Árido, nas diferentes formas de aquisição de recursos econômicos por meios de salários, de aposentadorias e dos tão conhecidos 'projetos' e suas influências na qualidade de vida dos indígenas.

O artigo seguinte da coletânea, de autoria de Áurea Fabiana de Albuquerque Gerum, uma economista, e Werner Doppler, estudioso alemão de sistemas agrícolas rurais nos trópicos, à primeira vista, parece muito técnico devido às várias tabelas e aos gráficos. Os autores discutiram, com base em dados empíricos, as relações entre a disponibilidade de terras, a renda das famílias e o uso dos recursos produtivos entre os Fulni-ô.

No último artigo da coletânea, Sérgio Neves Dantas abordou como as músicas Fulni-ô expressam aspectos da memória identitária e mística daquele povo indígena. $\bigcirc$ autor procurou também evidenciar a dimensão poética e sagrada dessa musicalidade. Sua análise baseia-se, sobretudo, na produção musical contemporânea gravada por grupos de índios Fulni-ô, como forma de afirmação da identidade étnica.

Publicado como primeiro volume da Série Antropologia e Etnicidade, sob os auspícios do Núcleo de Estudos e Pesquisas sobre Etnicidade (NEPE), um dos núcleos vinculados ao Programa de Pós-Graduação em Antropologia da UFPE, o livro é composto por sete artigos. É completado com uma relação bibliográfica comentada sobre os Fulni-ô, trazendo ainda, em anexo, vários documentos relativos às terras daquele povo indígena.

A publicação dessa coletânea é muito oportuna pelo fato de reunir um conjunto de textos com diferentes olhares e abordagens, que procuram fugir do exotismo, como também do simplismo em tratar sobre um povo tão singular, situado no contexto sociohistórico do que se convencionou chamar Nordeste brasileiro, onde a presença indígena foi em muito ignorada pelos estudos 
acadêmicos e deliberadamente negada, seja pelas autoridades constituídas, seja também pelo senso comum.

Diante do exíguo conhecimento que se tem sobre os Fulni-ô e da dispersão dos poucos estudos publicados a respeito daquele povo indígena, provavelmente a primeira edição dessa importante coletânea será brevemente esgotada. Pensando em uma segunda edição, seguem sugestões. A primeira diz respeito ao próprio título do livro, pois, na forma atual, os Fulni-ô aparecem como última parte do título: "Cultura, identidade e território no Nordeste indígena: os Fulni-ô". Para um efeito prático da referenciação bibliográfica, propomos uma inversão no título: os Fulni-ô: cultura, identidade e território no Nordeste indígena.

Sugerimos também a inclusão de mapas de localização, com destaque para o Nordeste, Pernambuco, o agreste e Águas Belas, onde habitam os Fulni-ô. A nosso ver, é tal mapa imprescindível, pois possibilitaria a visualização do povo indígena no contexto das relações históricas e socioespaciais onde o grupo está inserido. Sabemos que imagens, de uma forma em geral, encarecem a produção bibliográfica. Todavia, a inclusão de fotografias, ao menos em preto e branco, também enriqueceria e muito as abordagens dos textos.

Por fim, uma pergunta: para enriquecer mais ainda a coletânea, por que não acrescentar, na Introdução de uma possível reedição, os comentários dos Fulni-ô a respeito das leituras prévias dos textos antes da publicação, e como ocorreu a recepção daquele povo ao receber o livro publicado?

Lamentamos a ausência, na coletânea, de artigos da área de História. Infelizmente, frente ao pouco interesse de historiadores sobre a temática, colegas de outras áreas, principalmente da Antropologia, cada vez mais procuram suprir essa lacuna, realizando pesquisas em fontes históricas para embasarem seus estudos e suas reflexões a respeito dos povos indígenas.

Ainda para uma segunda edição ou um possível e merecido segundo volume da coletânea, lembramos o estudo "A extinção do Aldeamento do Ipanema em Pernambuco: disputa fundiária e a construção da imagem dos 'índios misturados' no século XIX", apresentado, em 2006, por Mariana Albuquerque Dantas como monografia de conclusão do curso de bacharelado em História, na UFPE (Dantas, 2006). A mesma autora defendeu na Universidade Federal Fluminense (RJ), em 2010, a dissertação de mestrado intitulada "História dinâmica social e estratégias indígenas: disputas e alianças no Aldeamento do Ipanema em Águas Belas, Pernambuco (1860-1920)" (Dantas, 2010). São duas pesquisas baseadas amplamente em fontes históricas disponíveis no Arquivo Público Estadual de Pernambuco e nas discussões da produção bibliográfica atualizada sobre os povos indígenas no Nordeste.

No momento em que a sociedade civil no Brasil, por meio dos movimentos sociais, principalmente na educação, questiona os discursos sobre uma suposta identidade cultural nacional, a publicação dessa coletânea reveste-se, portanto, de um grande significado. A afirmação da sociodiversidade no país, questionando a mestiçagem como ideia de uma cultura e da identidade nacional, significa o reconhecimento dos povos indígenas, a exemplo dos Fulni-ô, em suas diferentes expressões socioculturais.

Buscando compreender as possibilidades de coexistência sociocultural, fundamentada nos princípios da interculturalidade, Baniwa (2006, p. 51) escreveu:

\begin{abstract}
A interculturalidade é uma prática de vida que pressupõe a possibilidade de convivência e coexistência entre culturas e identidades. Sua base é o diálogo entre diferentes, que se faz presente por meio de diversas linguagens e expressões culturais, visando à superação de intolerância e da violência entre indivíduos e grupos sociais culturalmente distintos.
\end{abstract}

Essa coletânea é uma excelente referência tanto para pesquisadores especializados no estudo da temática indígena como para as demais pessoas interessadas no assunto, principalmente professores indígenas e não indígenas. Estes terão em mãos uma fonte de estudos sobre 
um tema com notória ausência de subsídios, objetivando atender as exigências da Lei 11.645/2008, que determinou a inclusão do ensino da história e das culturas dos povos indígenas nas escolas públicas e privadas no Brasil.

\section{REFERÊNCIAS}

BANIWA, Gersem dos Santos Luciano. O índio brasileiro: o que você precisa saber sobre os povos indígenas no Brasil de hoje. Brasília: MEC; Rio de Janeiro: Museu Nacional/UFRJ, 2006.
DANTAS, Mariana Albuquerque. História dinâmica social e estratégias indígenas: disputas e alianças no Aldeamento do Ipanema em Águas Belas, Pernambuco (1860-1920). 2010. Dissertação (Mestrado em História) - Universidade Federal Fluminense, Niterói, 2010.

DANTAS, Mariana Albuquerque. A extinção do Aldeamento do Ipanema em Pernambuco: disputa fundiária e a construção da imagem dos 'índios misturados' no século XIX. 2006. Monografia (Bacharelado em História) - Universidade Federal de Pernambuco, Recife, 2006.

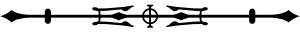

